\title{
A resolução de problemas no ensino da geometria: dificuldades e limites de graduandos de um curso de pedagogia
}

\author{
Problem solving in teaching geometry: difficulties and undergraduate limits of a course \\ of pedagogy
}

\author{
Érika Janine Maia \\ erikajaninemaia@gmail.com
}

Marcelo Carlos de Proença

mcproenca@uem.br

\begin{abstract}
Resumo
O objetivo foi evidenciar as dificuldades e os limites apresentados por licenciandos de um curso de Pedagogia para tratarem sobre a resolução de problemas no processo de ensino da geometria. Participaram 42 acadêmicos matriculados no quarto ano de um curso de Pedagogia de uma universidade pública, localizada no norte do estado do Paraná. Eles resolveram uma prova escrita composta por 10 problemas envolvendo o conteúdo de geometria dos anos iniciais, e de acordo com as notas obtidas nesta prova, foram selecionados quatro acadêmicos para serem entrevistados, individualmente. Os resultados revelaram que os futuros professores investigados encontram-se despreparados para ensinar matemática por meio da resolução de problemas.
\end{abstract}

Palavras-chave: Resolução de problemas; Anos iniciais do ensino fundamental; Formação de professores.

\begin{abstract}
The objective was to investigate the difficulties and limits presented by licensees of a Pedagogy course to address on problem solving in the teaching geometry. They participated in the work 42 students enrolled in the fourth year of a pedagogy course of a public university located in the north of Paraná state. They resolved a written test consisting of 10 problems involving geometry content of the initial years. According to the marks obtained in this test, four students were selected, which were individually interviewed. The results showed unpreparedness to teach mathematics through problem solving.
\end{abstract}

Keywords: Problem solving; Years elementary school initials; Teacher training.

\section{Introdução}

A investigação apresentada neste trabalho é referente a dados provenientes da dissertação de mestrado, cujo título é "Conhecimentos de estudantes de pedagogia sobre a resolução de problemas geométricos" que, de modo geral, investigou e analisou os conhecimentos sobre resolução de problemas geométricos que os estudantes de Pedagogia possuem e que se fazem necessários para a prática efetiva em sala de aula, dando ênfase para os problemas geométricos que envolvam figuras planas.

Diversas pesquisas tem evidenciado uma preocupação relacionada à formação inicial recebida pelo Pedagogo no que diz respeito ao ensino da Matemática. Vários fatores são apontados, tais como, a carga horária reduzida destinada a disciplinas que envolvam esta temática 
presente na grade curricular dos cursos de Pedagogia de todo Brasil, a falta de uniformidade e apontamentos legais que direcionem o tratamento que deverá ser dado ao trabalho com os saberes disciplinares de matemática para os anos iniciais do Ensino Fundamental, dentre outros fatores. (ALMEIDA; LIMA, 2012; CURI, 2004; FERREIRA; PASSOS, 2014; SOUSA; SOBRINHO, 2010).

A abordagem da resolução de problemas apresenta-se como um conhecimento pedagógico do conteúdo no ensino que é citado por Shulman (1986) como um dos saberes necessários a quem deseja ser professor. A pesquisa de Justo et al. (2015) apontou que a maneira como o professor ensina a resolução de problemas matemáticos faz diferença na aprendizagem do aluno. A resolução de problemas é uma atividade importante, entretanto, parece que as pessoas, de modo geral, sentem dificuldades em resolver problemas.

Segundo Almeida e Lima (2012), no atual modelo de educação o processo de aprendizagem da Matemática, em seu aspecto formal e sistematizado, inicia-se na Educação Básica nos primeiros anos do Ensino Fundamental, com professores que geralmente são licenciados em Pedagogia. Sousa e Sobrinho (2010) tendo em vista todas as competências que são exigidas a esses profissionais, afirmaram que é imprescindível que se faça um retorno à formação inicial do pedagogo.

Com o intuito de fazer este retorno, esta pesquisa buscou evidenciar quais são as dificuldades e os limites apresentados por licenciandos que estão matriculados no último ano de um curso de graduação em Pedagogia, futuros professores dos anos iniciais do Ensino Fundamental, para tratarem sobre a resolução de problemas no processo de ensino da geometria.

\section{A Matemática na formação inicial do Pedagogo}

Ferreira e Passos (2014) apresentaram em seu trabalho pesquisas que apontam para um crescimento considerável de estudos voltados para a formação de professores que ensinam Matemática nos anos iniciais do Ensino Fundamental (CURI, 2004; GATTI; NUNES, 2009).

Nos resultados apontados nas pesquisas analisadas, é comum aparecerem relatos de graduandos em Pedagogia indicando que o ensino da Matemática não é priorizado durante sua formação. Segundo Almeida e Lima (2012), os conteúdos que fazem parte do conhecimento da Matemática estão relegados a um segundo plano na formação do pedagogo. $\mathrm{O}$ trabalho de Lima e Martins (2012) apontou que 
É comum ouvir dos professores em formação, ou recém-formados, que os cursos não abordam a matemática que devem ensinar aos seus alunos e ainda que nenhuma relação seja estabelecida entre a matemática ensinada nas instituições de ensino superior e a matemática que deve ser ensinada na educação básica. Dessa forma, o conhecimento necessário ao exercício no campo de atuação é construído pelo professor na sala de aula. (LIMA; MARTINS, 2012, p.7)

O parecer CNE/CP 9/2001 indica que é necessário que o aluno veja com clareza qual a relação entre o que ele está aprendendo na licenciatura e o currículo que ensinará no segundo segmento do Ensino Fundamental, ou seja, é importante que o professor que está atuando no processo de formação deste aluno e o projeto pedagógico do curso de licenciatura forneçam subsídios suficientes para que ocorra esta articulação. Além disso, é função dos cursos de preparação de futuros professores suprir as eventuais deficiências de escolarização básica que eles receberam tanto no Ensino Fundamental como no Ensino Médio.

Com relação aos conteúdos matemáticos presentes nos cursos de Pedagogia, Curi (2004) apontou que não há uma uniformidade e nem ao menos apontamentos legais que direcionem o tratamento que deverá ser dado ao trabalho com os saberes disciplinares de Matemática para as séries iniciais do Ensino Fundamental. Logo, cada instituição, obedecendo às diretrizes curriculares, na elaboração do Projeto Pedagógico deve apontar com clareza qual conteúdo matemático e quando ele deverá ser trabalhado com os licenciandos.

Curi (2004) realizou uma análise em ementas de trinta e seis cursos de Pedagogia nas disciplinas da área de Matemática de instituições que haviam reformulado suas grades curriculares a partir do ano de 2000. Nessa análise, constatou diferenças relevantes ao número e aos nomes de disciplinas, em termos da bibliografia utilizada e do perfil do formador. Segundo a autora, à disciplina que trata dos conhecimentos didáticos dos conteúdos matemáticos é denominada nas grades curriculares como Metodologia do Ensino de Matemática.

Para Ferreira e Passos (2014, p.1810) ao realizar estudos sobre essas disciplinas de Metodologia do Ensino de Matemática verifica-se "uma carga horária reduzida e insuficiente para uma abordagem significativa de conteúdos, fundamentos e métodos, indicando, possivelmente, lacunas na formação do professor".

$\mathrm{Na}$ instituição na qual foi realizada esta pesquisa, o curso apresenta duas disciplinas obrigatórias na área da Matemática: Metodologia do Ensino de Matemática - $1^{\mathrm{a}}$ a $4^{\mathrm{a}}$ séries do Ensino Fundamental I, com carga horária de 68 h/a, e Metodologia do Ensino de Matemática - $1^{\mathrm{a}}$ a $4^{\mathrm{a}}$ séries do Ensino Fundamental II com a mesma carga horária de 68 horas aulas. Sendo assim, ao decorrer de toda a graduação os acadêmicos do curso possuem apenas 136 
h/a voltadas para as disciplinas específicas de Matemática, o que representa aproximadamente 4\% da carga horária total do curso que corresponde a 3276 horas.

\section{A resolução de problemas no ensino da geometria}

Uma das principiais dificuldades dos professores está em saber diferenciar o que é um problema de um exercício. Segundo Echeverría (1998) para que uma situação seja classificada como problema é preciso que existam obstáculos entre a proposição e a meta. Assim, para que uma determinada situação seja caracterizada como um verdadeiro problema para os alunos que irão resolvê-la é necessário que se constitua em um real desafio em que os alunos buscarão por meio de uma sequência de ações ou operações obter resultados.

Com relação aos exercícios, Echeverría (1998) afirma que estes podem ser classificados em dois grupos: o primeiro faz referência à repetição de uma determinada técnica, previamente exposta pelo professor. Neste caso, o professor insere o conteúdo a ser estudado e logo em seguida passa algumas atividades que deverão ser realizadas pelos alunos para treinarem a técnica ensinada. Já o segundo tipo de exercício não pretende somente que sejam automatizadas uma série de técnicas, mas também que sejam aprendidos alguns procedimentos nos quais se inserem essas técnicas.

Schroeder e Lester (1989) elencaram três abordagens de ensino que diz respeito a resolução de problemas, a saber: ensinar sobre resolução de problemas, ensinar para resolução de problemas e ensinar via resolução de problemas.

Na concepção dos autores, o ensinar sobre resolução de problemas, quanto a seus processos, refere-se ao ensino baseado no modelo de Polya, em que os alunos ao resolverem um problema, deveriam se remeter as quatro fases elencadas por ele. $\mathrm{O}$ ensinar para resolução de problemas corresponde a um ensino que se direciona, primeiro, a levar os alunos a aprenderem conteúdos de matemática para, somente depois, aplicarem em problemas e exercícios. Por fim, o ensinar via resolução de problemas corresponde a um ensino que preza pela utilização de problemas como primeiro passo para aprender Matemática. (SCHROEDER; LESTER, 1989).

Quanto às fases/etapas da resolução de problemas, Brito (2006) analisou pesquisas sobre aspectos teóricos desse processo e o sintetizou em: representação, planejamento, execução e monitoramento. Sobre a fase/etapa da representação do problema, entende-se que consiste na interpretação ou compreensão do problema por aquele que o soluciona. $\mathrm{Na}$ etapa de planejamento, o solucionador de problemas deve buscar estratégias que o leve ao sucesso. Já à execução da estratégia é realizada com base em uma ação procedimental em cálculos, 
desenhos e outras formas de representações. A última fase/etapa, o monitoramento, corresponde ao ato de avaliar a solução obtida.

Sobre a resolução de problemas para o ensino da geometria, encontra-se na literatura autores que apontam que os conceitos geométricos não devem ser trabalhados desvinculados das situações problemas. (PAVANELLO, 1993; PIROLA, 2000). A geometria é um conteúdo necessário para a solução de problemas geométricos, visto que os conceitos geométricos constituem parte importante do currículo de Matemática no Ensino Fundamental.

Fazendo relação entre a geometria e a resolução de problemas Farrel (1994), indicou que a geometria

[...] parece adequar-se especialmente a atividades de resolução de problemas. Tudo indica que a compreensão da geometria se aprofunda à medida que os alunos interagem para analisar construções, descobrir demonstrações ou para encontrar um modelo geométrico que melhor se ajuste a uma situação problema. Porém, o medo do conteúdo pode ser um impedimento para o êxito na resolução de problemas. Assim, no início de um curso, as atividades de resolução de problemas deveriam ter um alto potencial de sucesso para a maioria dos alunos. (FARREL,1994, p.296).

A maneira pela qual o conteúdo será trabalhado com os alunos está diretamente relacionada com a formação recebida pelo professor que conduzirá a aula. Segundo Pirola (2000) uma formação deficitária deste professor, em especial na geometria, poderá levá-lo a ensinar somente aquilo que ele gosta, deixando para segundo plano tópicos importantes referentes ao assunto a ser abordado. Para este autor, um dos motivos da geometria não ser ensinada nas escolas decorre da falta de preparação dos professores que muitas vezes não conseguem solucionar problemas simples de geometria.

\section{Metodologia}

Este trabalho se configura como um estudo de abordagem qualitativa em que os dados são construídos e o pesquisador é visto como o principal instrumento de investigação, uma vez que possui a necessidade de contato direto e prolongado com o campo, para poder captar os significados dos comportamentos observados (ALVES-MAZZOTTI; GEWANDSZNAJDER, 2002).

Assim, para identificar e analisar as dificuldades e os limites sobre a resolução de problemas no ensino da geometria que são apresentados por estudantes de Pedagogia investigou-se 42 alunos que estavam matriculados em duas turmas do quarto ano desse curso, oferecido em uma universidade pública do interior do Estado do Paraná. A escolha desses participantes se deu pelo fato de já terem cursado durante a graduação as disciplinas referentes à metodologia do ensino de Matemática, que provavelmente lhes forneceu subsídios para discorrerem sobre o ensino da geometria. 
Aplicou-se a esses participantes uma prova escrita, composta de dez problemas. Tal prova, de cunho dissertativo, visava avaliar como os licenciandos abordam um problema matemático, como o compreendem, as estratégias utilizadas, formas de relacionar e conjecturar ideias e questões, seleção de procedimentos, interpretação dos dados e relatos dos resultados. A prova foi elaborada de acordo com os descritores apresentados na matriz de referência da Prova Brasil:

- D1: identificar a localização/movimentação de objeto em mapas, croquis e outras representações gráficas;

- D4: identificar quadriláteros observando as relações entre seus lados (paralelos, congruentes, perpendiculares);

- D5: reconhecer a conservação ou modificação de medidas dos lados, do perímetro, da área em aplicação e/ou redução de figuras poligonais usando malhas quadriculadas;

- D7: resolver problemas significativos utilizando unidades de medidas padronizadas como $\mathrm{km} / \mathrm{m} / \mathrm{cm} / \mathrm{mm}$;

- D11: resolver problemas envolvendo o cálculo do perímetro de figuras planas, desenhadas em malhas quadriculadas;

- D12: resolver problemas envolvendo o cálculo ou estimativa de áreas de figuras planas, desenhadas em malhas quadriculadas.

A análise dos dados nesta prova escrita foi realizada em termos das notas médias obtidas, relatos das dificuldades para resolver os problemas, e nas etapas de resolução de problemas de Brito (2006). Com base nestas notas, selecionou-se dois alunos que obtiveram a maior nota (4N.6 e 4N.4) e dois alunos que obtiveram a menor nota (4N.5 e 4N.16) para serem entrevistados.

Segundo Tozoni-Reis (2010, p.26), a entrevista "é uma das técnicas muito presentes na etapa da coleta de dados da pesquisa qualitativa, em especial, no trabalho de campo. Ela tem como objetivo buscar informações na "fala" dos entrevistados". Nesta pesquisa, utilizou-se as entrevistas semiestruturadas que, para Fiorentini e Lorenzato $(2009$, p.121) são aquelas em que "o pesquisador, pretendendo aprofundar-se sobre um fenômeno ou questão específica, organiza um roteiro de pontos a serem contemplados durante a entrevista", podendo, de acordo com o desenvolvimento desta, alterar a ordem deles e, até mesmo, formular questões não previstas inicialmente.

Assim, as entrevistas com os licenciandos selecionados foram áudio-gravadas e realizadas individualmente em data, horário e local, providenciados de acordo com a disponibilidade dos participantes.

As entrevistas buscavam evidenciar os conhecimentos dos participantes sobre a resolução de problemas no ensino da geometria. Para tanto, elaborou-se um roteiro, contendo sete questões, que podem ser observadas no quadro 1 . 
Quadro 1: Roteiro para a entrevista

\begin{tabular}{|c|c|}
\hline \multicolumn{2}{|r|}{ ROTEIRO } \\
\hline 1 & $\begin{array}{l}\text { Comente sobre sua trajetória de vida até sua opção pelo curso superior que está matriculado e a formação } \\
\text { nele realizada }\end{array}$ \\
\hline 2 & Para você, o que é um problema? E um exercício? \\
\hline 3 & $\begin{array}{l}\text { Fazendo referência à quando você era aluno da Educação Básica: } \\
\text { a) Os seus professores trabalhavam problemas em suas aulas? } \\
\text { b)E problemas de geometria? Em caso afirmativo, como era essa abordagem realizada por eles em sala } \\
\text { de aula? } \\
\text { c) Como você era avaliado na resolução de problemas geométricos? Comente }\end{array}$ \\
\hline 4 & Caso você fosse ministrar uma aula de geometria utilizando a resolução de problemas, como faria? \\
\hline 5 & Tem algum conteúdo de geometria que você não gostaria de ensinar? Explique \\
\hline 6 & $\begin{array}{l}\text { Em suas aulas de geometria durante a graduação, quais estratégias você aprendeu para ensinar este } \\
\text { conteúdo? }\end{array}$ \\
\hline 7 & $\begin{array}{l}\text { Você acredita que o curso de Pedagogia desta Universidade modificou/ampliou seus conhecimentos sobre } \\
\text { geometria e o seu ensino por meio da resolução de problemas? }\end{array}$ \\
\hline
\end{tabular}

Fonte: Os autores.

As análises das entrevistas seguiram a Análise de Conteúdos proposta por Bardin (1977) que é organizada por meio de três fases, identificadas pela autora como polos cronológicos:

1) Pré-análise: neste momento, as entrevistas passaram pelo processo de transcrição para que trechos pudessem ser selecionados de forma a evidenciar os conhecimentos dos participantes sobre a resolução de problemas no ensino de geometria. Foi realizada a leitura flutuante destes materiais que segundo Bardin (1977) é o momento em que o pesquisador estabelece contato com os documentos que serão analisados, conhecendo todas as respostas e deixando-se invadir por impressões e orientações.

2) Exploração do material: realizou-se uma organização e preparação do material a ser investigado a fim de interpretá-lo. Bardin (1977) afirma que para tratar o material é necessário codificá-lo. Sendo assim, a codificação dos materiais estabeleceu um código que possibilitou que cada elemento da amostra fosse identificado, permitindo que a pesquisadora pudesse retornar a um documento específico quando fosse preciso. Logo, a identificação de cada sujeito da pesquisa acompanha o ano que o aluno está matriculado (4), o turno que frequenta (N) e um número aleatório que sua prova recebeu.

3) Tratamento dos resultados, inferência e interpretação: os resultados passam a ganhar significados. Segundo Bardin (1977, p.101), "os resultados brutos são tratados de maneira a serem significativos (falantes) e válidos".

Dessa forma, os dados foram sistematizados e agrupados em três categorias: 1) Resolução de problemas/Exercícios; 3) Ensino da geometria por meio da resolução de problemas; 4) Formação no curso de Pedagogia.

Essas categorias emergiram das respostas apresentadas pelos investigados. Para isso, foram considerados todos os depoimentos em sua totalidade e em seguida formados agrupamentos 
com as preposições similares a fim de obter dados sistematizados. Essas preposições são conhecidas como unidades de registro que podem ser palavras, frases, parágrafos que sejam comparáveis e tenham o mesmo conteúdo semântico.

\section{Análise e discussão dos dados das entrevistas}

Nesta seção é realizada uma discussão sobre os dados coletados durante as entrevistas a fim de evidenciar quais são as dificuldades e limites dos graduandos para trataram sobre resolução de problemas e o seu ensino.

O quadro 2 faz referência à categoria "Resolução de problemas/Exercícios".

Quadro 2: Agrupamento da categoria resolução de problemas/Exercícios

\begin{tabular}{|c|c|c|c|}
\hline Categoria & Subcategoria & Unidade de Registro & Unidade de contexto \\
\hline \multirow{8}{*}{$\begin{array}{l}\text { Resolução } \\
\text { de } \\
\text { problemas } \\
\text { /Exercício } \\
\text { s }\end{array}$} & \multirow{4}{*}{ Exercícios } & \multirow{4}{*}{$\begin{array}{l}\text { Relacionado às contas, } \\
\text { exercitar o que a criança } \\
\text { já aprendeu, é mecânico }\end{array}$} & 4N.5: Exercício são contas \\
\hline & & & $\begin{array}{l}\text { 4N.4: Pra exercitar aquilo que ele já sabe, pra fixar aquilo } \\
\text { que ele já conhece, que já foi passado em sala }\end{array}$ \\
\hline & & & $\begin{array}{l}\text { 4N.6: Um exercício geralmente é algo pra repetir aquilo } \\
\text { que a criança já sabe, mais técnico }\end{array}$ \\
\hline & & & $\begin{array}{l}\text { 4N.16: exercício é uma coisa mais mecânica, é uma coisa } \\
\text { assim, dá uma conta pra você resolver }\end{array}$ \\
\hline & \multirow{4}{*}{ Problemas } & \multirow{4}{*}{$\begin{array}{l}\text { Algo que leva a criança a } \\
\text { pensar }\end{array}$} & $\begin{array}{l}\text { 4N.5: no problema há várias contas, há várias etapas pra } \\
\text { você resolver um problema que você precisa pensar }\end{array}$ \\
\hline & & & $\begin{array}{l}\text { 4N.4: Dentro da matemática, um problema... ai, algo que } \\
\text { tem que ser resolvido, que envolve raciocínio, algo que } \\
\text { você tem que pensar, você tem que analisar todos os } \\
\text { dados que você tem pra você descobrir o resultado }\end{array}$ \\
\hline & & & $\begin{array}{l}\text { 4N.6: problema é você colocar a criança num desafio, } \\
\text { realmente pensar }\end{array}$ \\
\hline & & & $\begin{array}{l}\text { 4N.16: problemas é você fazer a criança pensar, fazer ela } \\
\text { raciocinar a base de um problema, acho que de um } \\
\text { problema que acontece assim relacionada ao cotidiano } \\
\text { dela }\end{array}$ \\
\hline
\end{tabular}

Fonte: Os autores.

Para esta autora, um exercício pode ser outro tipo de tarefa na qual o aluno não precisa tomar nenhuma decisão sobre os procedimentos adequados à solução.

Já na segunda subcategoria, a unidade de registro relacionada à definição do que seria um problema foi 'algo que leve a criança a pensar'. A resposta do sujeito 4N.6 ao compreender o problema como um desafio está de acordo com a definição de Echeverría (1998) em que para uma situação ser caracterizada como um verdadeiro problema, é necessário que ela se constitua em um real desafio em que os alunos buscarão por meio de uma sequência de ações ou operações obter resultados. 
O participante 4N.5 ao relatar o que era um problema, disse que haviam várias etapas, e quando questionado pela pesquisadora sobre quais seriam essas etapas, respondeu: "Etapa... ah.... Qual é o problema, achar a divisão, a multiplicação pra chegar num resultado final... é isso". O aluno não se referiu as quatro etapas da resolução de problemas propostas por Brito (2006). Analisando sua fala, as etapas seriam identificar um problema (qual é o problema), executar uma estratégia (achar a divisão, a multiplicação) e encontrar a solução.

Com relação a essas etapas de Brito (2006) vemos que aparecem nas respostas dos participantes indícios sobre as etapas de representação, planejamento e execução. Apesar disto, nada foi citado sobre a etapa do monitoramento:

Na subcategoria exercícios, a unidade de registro foi 'relacionado às contas, exercitar o que a criança já aprendeu, é mecânico'. Segundo Echeverría (1998) os exercícios não são apenas contas, ou seja, repetições das operações matemáticas como foi relatado pelos entrevistados.

4N.6 "Recolher os dados dos problemas, escrever a fórmula, adequar os dados na fórmula, resolver".

4N.4: "Ler o problema, descrever as informações dadas, entender a pergunta, usar fórmulas se possivel".

4N.16: "Compreensão do problema, levantamento dos dados, reflexão em torno de que conta/fórmula usar e por fim, obtenção do resultado".

No quadro 3, encontra-se as categorias relacionadas ao ensino da geometria por meio da resolução de problemas (RP).

Quadro 3: Agrupamento da categoria Ensino da Geometria por meio da RP

\begin{tabular}{|c|c|c|c|}
\hline Categoria & Subcategoria & $\begin{array}{c}\text { Unidade de } \\
\text { Registro }\end{array}$ & Unidade de contexto \\
\hline \multirow{8}{*}{$\begin{array}{l}\text { Ensino da } \\
\text { Geometria } \\
\text { por meio da } \\
\text { RP }\end{array}$} & \multirow{4}{*}{$\begin{array}{l}\text { Dificuldades } \\
\text { para ensinar }\end{array}$} & \multirow{4}{*}{$\begin{array}{l}\text { Todos os } \\
\text { conteúdos, } \\
\text { citando: área e } \\
\text { fórmulas }\end{array}$} & 4N.5: Tudo \\
\hline & & & $\begin{array}{l}\text { 4N.4: o cálculo que já começa usar umas fórmulas } \\
\text { diferentes }\end{array}$ \\
\hline & & & 4N.6: talvez tudo, todos os conteúdos. \\
\hline & & & $\begin{array}{l}\text { 4N.16: calcular área. Eu acho que é bem difícil de explicar } \\
\text { também }\end{array}$ \\
\hline & \multirow{4}{*}{$\begin{array}{l}\text { Como realizaria } \\
\text { este ensino em } \\
\text { sala de aula }\end{array}$} & \multirow{4}{*}{ Preciso estudar } & $\begin{array}{l}\text { 4N.5: eu teria que ter um tempo hábil pra eu poder me } \\
\text { socializar com o conteúdo }\end{array}$ \\
\hline & & & $\begin{array}{l}\text { 4N.4: acho que é complicado né a gente dizer... não sei, } \\
\text { não sei }\end{array}$ \\
\hline & & & 4N.6: teria que me aprofundar um pouco \\
\hline & & & $\begin{array}{l}\text { 4N.16: eu ia ter que estudar de novo sabe, porque eu não } \\
\text { lembro }\end{array}$ \\
\hline
\end{tabular}

Fonte: Os autores. 
Nesta categoria, destaca-se a fala do sujeito 4N.5 que quando questionado sobre qual a importância de ensinar geometria relatou que está não deveria ser ensinada: “É, porque assim...quando a gente vai pra escola a geometria é menos focada. Eles aprendem a somar, dividir, subtrair e multiplicar, o resto é um complemento que se trabalha uma, duas vezes. Sempre é deixado pro fim de ano. Então não, mas não no sentido que não se deve. Deve ensinar, mais pra quem tem o hábito, prazer de ensinar, porque não adianta eu querer ensinar uma criança sem gostar. Porque eu não gosto, eu sou sincera".

$\mathrm{Na}$ fala deste aluno nota-se que ele concebe a geometria como algo secundário frente aos outros conteúdos matemáticos. Enfatiza a importância das quatro operações e alega que a geometria é deixada para o fim do ano. Esta concepção está de acordo com um dos apontamentos de Fonseca et al. (2011) que relatou que os professores acabam deixando a geometria para ser trabalhada no fim do período letivo.

Em seguida, o entrevistado argumenta que só deve ensinar a geometria quem gosta deste conteúdo, caso contrário não adiantaria. Diante desta resposta, questionou-se como ele faria para ensinar este conteúdo, visto que como professor dos anos iniciais certamente terá que ensiná-los, sua resposta foi: "eu sei que eu vou ter que aprender a gostar pra poder ensinar, porque não adianta eu não gostar e ensinar mal ensinado". Quando perguntamos se ele já precisou ministrar alguma aula de Matemática afirmou: "No estágio ano passado, minha amiga que fez tudo, porque eu não me sinto preparada".

É extremamente preocupante o fato deste aluno apresentar estas respostas, visto que ele está inserido em um curso de formação de professores, matriculado no último semestre da graduação, e será um profissional que possivelmente irá atuar nos anos iniciais da escolarização. Segundo Almeida e Lima (2012, p.457), são nestes anos escolares que deveriam ser construídas as bases para a formação matemática dos alunos.

Para esses autores, a competência básica de todo e qualquer professor é o domínio do conteúdo específico, "haja vista que o conteúdo específico de matemática continua sendo um importante instrumento de trabalho do professor na construção das habilidades e competências matemáticas requeridas pelo aluno e pela sociedade”.

Quando questionados sobre como ensinariam geometria para seus alunos por meio da resolução de problemas, os entrevistados disseram que primeiramente precisariam estudar sobre o assunto para então pensar em alguma estratégia de ensino. O sujeito 4N.16 disse que “tentaria não passar exercícios, mais passar alguma coisa pra eles raciocinar mais, acho que pra eles internalizar mais. Porque se for só a base de exercícios eles vão esquecer logo. [...]”. 
Sobre seus conhecimentos a respeito do ensino de geometria por meio da resolução de problemas o acadêmico 4N.6 relatou "eu acho que não é um assunto fácil de lidar e principalmente é uma coisa que eu penso que é muito abstrato na minha cabeça ainda, eu não consigo muito materializar a geometria [...]é algo que fica muito confuso, talvez pela formação".

O sujeito 4N.4, afirmou que não saberia como conduzir uma aula que envolve a resolução de problemas para o ensino de conteúdos geométricos e que procuraria trabalhar com a realidade do aluno.

Com base nos relatos apresentados pelos acadêmicos, evidenciam-se as dificuldades que eles possuem para escrever e falar sobre o ensino da geometria na sala de aula. No que diz respeito ao uso da resolução de problemas para esse ensino, o sujeito 4N.16 apresentou indícios de que visa um ensino para a resolução de problemas, uma vez que ele explicaria os conceitos e em seguida trabalharia com problemas. Os outros entrevistados mesmo quando questionados sobre o assunto, disseram não saber responder. Este fato evidencia que, em específico, o ensino da geometria por meio da resolução de problemas não foi discutido durante a graduação.

Na terceira categoria, "Formação no curso de Pedagogia", apresenta-se o quadro 4.

Quadro 4: Agrupamento da categoria formação no curso de Pedagogia

\begin{tabular}{|c|c|c|c|}
\hline Categoria & Subcategoria & $\begin{array}{l}\text { Unidade de } \\
\text { Registro }\end{array}$ & Unidade de contexto \\
\hline & \multirow{4}{*}{$\begin{array}{l}\text { Estratégias de ensino } \\
\text { para a geometria durante } \\
\text { a graduação }\end{array}$} & \multirow{4}{*}{$\begin{array}{l}\text { Não estudamos/ } \\
\text { Não lembro }\end{array}$} & 4N.5: Isso tá na ementa, mas a gente não estudou \\
\hline & & & $\begin{array}{l}\text { 4N.4: ela [professora] passou estratégias pra nós } \\
\text { mas sem ter nada em mãos eu não me recordo }\end{array}$ \\
\hline & & & $\begin{array}{l}\text { 4N.6: Não lembro, mas acho que começar do mais } \\
\text { geral e depois ir para as particularidades }\end{array}$ \\
\hline & & & $\begin{array}{l}\text { 4N.16: o tempo foi muito curto e não deu tempo } \\
\text { dela passar }\end{array}$ \\
\hline & & \multirow[b]{2}{*}{$\begin{array}{l}\text { Construção dos } \\
\text { sólidos geométricos } \\
\text { e sua manipulação } \\
\text { para cálculo de } \\
\text { área, perímetro, } \\
\text { vértices, faces e } \\
\text { arestas. Tempo não } \\
\text { foi suficiente. }\end{array}$} & $\begin{array}{l}\text { 4N.5: Fizemos um trabalho dentro da sala de aula } \\
\text { colando [...] Deixou a desejar muito. Só era } \\
\text { exercícios }\end{array}$ \\
\hline & $\begin{array}{l}\text { Como foi o ensino da } \\
\text { geometria na graduação }\end{array}$ & & $\begin{array}{l}\text { 4N.4: ela [a professora] ia apresentando como a } \\
\text { gente tinha que trabalhar com o aluno. Ela trouxe } \\
\text { formas, ela trabalhou com sólidos, nós construímos } \\
\text { os sólidos das formas. Daí a partir daquilo a gente } \\
\text { tinha que descobrir número de arestas e daí assim } \\
\text { ela foi passando as fórmulas pra nós, mais primeiro } \\
\text { nós tínhamos que ir descobrindo ver se nós } \\
\text { conseguíamos descobrir a fórmula pra vértice, } \\
\text { faces, arestas }\end{array}$ \\
\hline
\end{tabular}




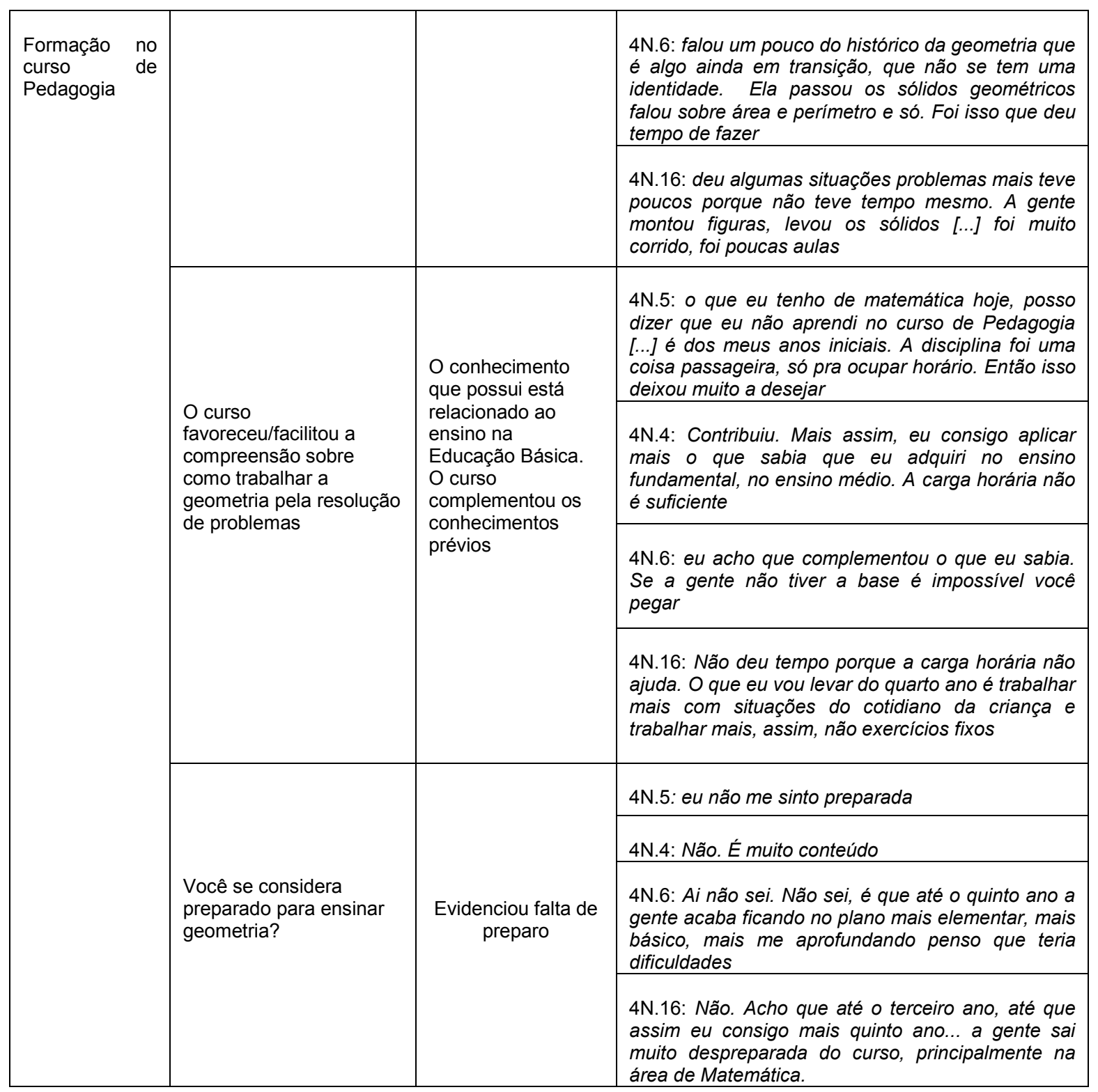

Fonte: Os autores.

A primeira subcategoria listada no quadro 4 buscou evidenciar quais são as estratégias de ensino para a geometria que os alunos aprenderam durante a graduação e foi apresentado como unidade de registro: 'não estudamos/não lembro'. Na segunda subcategoria 4N.6 disse "iniciou colocando sólidos na mesa e falando, perguntando pra gente quais eram as diferenças de uns pra outros, como que a gente poderia diferenciar o porquê que um era diferente do outro por que aquele se constitui como cubo, por que aquele se constitui como esfera, qual era a diferença entre eles", logo verifica-se que foram utilizados materiais manipuláveis para o ensino da geometria.

$\mathrm{Na}$ terceira subcategoria que apresentou como unidade de registro 'o conhecimento que possui está relacionado ao ensino na Educação Básica e que o curso complementou os 
conhecimentos prévios', o aluno 4N.6 relatou “Como talvez a gente já tinha uma base, pra mim não ficou tão difícil porque eu já conhecia né, essa foi uma forma de relembrar mais foi pouco (risos), bem pouco”.

O entrevistado 4N.16 ao se referir sobre as condições que o curso proporciona para tratar do ensino da geometria por meio da resolução de problemas disse "a gente sai muito despreparado do curso, principalmente na área de Matemática. E nas outras disciplinas também, ciências, geografia porque assim, os professores eles passam a metodologia e não acaba aplicando. Então acho que deveria ter mais um ano do curso", e continuou "Se a gente for pegar o livro e estudar dá pra fazer sabe, mais não dá pra ter aquela segurança pra passar para o aluno. Isso que é difícil. Eu acho que precisaria mais, eu acho que precisaria pelo menos uns três anos de Matemática". Para o licenciando 4N.5 "nós que estamos no último ano vamos ter que aprender por conta própria".

Este fato ficou claro na quarta subcategoria, "Você se considera preparado para ensinar geometria?', em que a unidade de registro foi 'evidenciou falta de preparo'. Portanto, observa-se nesta pesquisa que os futuros professores investigados, mesmo ao final de um curso de formação inicial, continuam demonstrando dificuldades e limites para falarem sobre a resolução de problemas. A fala do sujeito 4N.16 durante a entrevista quando questionado se já ministrou em sala de aula algum conteúdo que utilizasse a resolução de problemas mostrou o seu despreparo e insegurança sobre o assunto: "Graças a Deus ainda não, senão eu estava perdida”.

Em todas as categorias abordadas foi perceptível a preocupação dos licenciandos quanto à carga horária do curso destinada as disciplinas que envolvem a Matemática. Para o sujeito 4N.4 "Deveria ter mais. A gente fala assim: ah! Matemática no terceiro e no quarto ano. Mais quando vai ver é muito pouco pra se trabalhar porque a gente vai ter que aplicar. É muito conteúdo." e segundo o 4N.16 "deveria ter mais. A carga horária é muito pequena. Muito conteúdo pra pouco tempo.”. Neste sentido, concordamos com Curi (2006) ao afirmar que é necessário que os cursos de formação de professores que atuarão nos anos iniciais repensem o ensino que vem oferecendo a seus alunos, e a carga horária destinada as disciplinas que envolvam o ensino da Matemática.

\section{Conclusão}

Nesta pesquisa, o objetivo foi evidenciar as dificuldades e os limites dos acadêmicos que estão matriculados no último ano de um curso de graduação em Pedagogia para tratarem sobre a resolução de problemas no ensino da geometria. 
Evidenciou-se que os participantes compreendem o que é um problema e um exercício, porém quando questionados sobre quais seriam às etapas da resolução de problemas, referiram-se à representação, planejamento e execução, porém desconheciam a necessidade/importância de realizarem o monitoramento na solução obtida. Desta forma, verificou-se que durante a formação proporcionada pelo curso de graduação desta IES não foram realizadas discussões que envolviam esta temática.

Os dados mostraram, de forma geral, que não foi abordada uma formação para tratar da resolução de problemas no ensino de geometria durante o curso de graduação dos participantes. Segundo os depoimentos, as estratégias de ensino giravam em torno do uso dos sólidos geométricos e jogos, revelando limites para abordar a resolução de problemas em sala de aula, no caso, para tratar de um ensino via resolução de problemas.

Ficou evidente uma desmotivação com relação ao ensino da Matemática, em especial ao ensino da geometria, como pode ser observado na fala do sujeito 4N.5: "Você viu a reação nossa naquele dia (se referindo ao dia em que a prova escrita foi aplicada), eu até brinquei: 'Ai eu já passei nessa disciplina e vem me atormentar no último semestre de novo com a

\section{Matemática'”.}

Contudo, as dificuldades e limites identificados nesse estudo mostram que os futuros pedagogos investigados estão pouco preparados para ensinar matemática por meio da resolução de problemas. Portanto é necessário que nos cursos de formação de professores em Pedagogia se procure articular os conteúdos matemáticos aos conhecimentos pedagógicos que envolvem um ensino por meio da resolução de problemas. Além disso, é importante rever se a carga-horária de disciplinas de Matemática é suficiente para formar o futuro Pedagogo.

Entendemos que a nossa pesquisa possibilita uma reflexão sobre a formação de professores dos cursos de Pedagogia, sobre a desmotivação encontrada para o ensino da geometria, sobre o desconhecimento de como abordá-la em sala de aula e sobre a estrutura das grades curriculares desses cursos. Dentre essas e as outras dificuldades e limites elencados, verificamos que a formação de professores que atuarão nos anos iniciais e ministrarão a disciplina de Matemática carece de uma atenção especial.

\section{Referências}

ALMEIDA, M. B; LIMA, M. G. Formação inicial de professores e o curso de pedagogia: reflexões sobre a formação matemática. Ciência \& Educação, v. 18, n. 2, p. 451-468, 2012. 
ALVES-MAZZOTTI, A. J.; GEWANDSZNADJER, F. O método nas ciências naturais e sociais: pesquisa quantitativa e qualitativa. 2. ed. São Paulo: Pioneira Thomson Learning, 2002, 203p.

BARDIN L. L’Analyse de contenu. Editora: Presses Universitaires de France, 1977.

BRITO, M. R. F. Alguns aspectos teóricos e conceituais da solução de problemas matemáticos. In: BRITO, M. R. F. (Org.). Solução de problemas e a matemática escolar. Campinas, Alínea, 2006, 280p., p. 13-53.

CURI, E. Formação de professores dos anos iniciais: uma análise de conhecimentos para ensinar Matemática e de crenças e atitudes que interferem na constituição desses conhecimentos, São Paulo: 2004. Tese (Doutorado em Educação Matemática), PUC/SP.

CURI, E. A formação matemática de professores dos anos iniciais do ensino fundamental face às novas demandas brasileiras. Revista Iberoamericana de Educación (Online), Publicação Eletrônica pela OEI, v. 37, p. 01-09, 2006.

ECHEVERRÍA, M. P. P. A solução de problemas em matemática. In: POZO, J. I. (Org.). A solução de problemas: aprender a resolver, resolver para aprender. Porto Alegre: ArtMed,1998, 177p., p. 43-65.

FARRELL, M. A. Geometria para professores da escola secundária. In: LINDQUIST, M. M.; SHULTE, A. P. Aprendendo e ensinando Geometria. São Paulo: Atual, 1994, p. 290-307.

FERREIRA, V. L.; PASSOS, L. F. A metodologia do ensino de matemática no curso de pedagogia: o que as pesquisas vem apontando nos últimos dez anos? In: II CONGRESSO NACIONAL DE PROFESSORES E XII CONGRESSO ESTADUAL PAULISTA SOBRE FORMAÇÃO DE EDUCADORES. Anais... Águas de Lindóia, SP, 2014.

FIORENTINI, D.; LORENZATO, S. Investigação em educação matemática: percursos teóricos e metodológicos. 3. ed. Campinas: Autores Associados, 2009.

FONSECA, M. C. F. R., et al. O Ensino de Geometria na Escola Fundamental: três questões para a formação do professor dos ciclos iniciais. Belo Horizonte: Autêntica Editora, 2011, 3. ed.

GATTI, B. A.; NUNES, M. M. R. Formação de professores para o ensino fundamental: estudo de currículos das licenciaturas em Pedagogia, Língua Portuguesa, Matemática e Ciências Biológicas. Coleção Textos FCC. v. 29. São Paulo: Fundação Carlos Chagas, 2009.

JUSTO, J. C. R.; SANTOS, J. F.; BORGA, M. F.; REBELO, K. F. Desempenho de alunos dos anos iniciais do ensino fundamental na resolução de problemas aditivos e multiplicativos. In: CONFERENCIA INTERAMERICANA DE EDUCACIÓN MATEMÁTICA, 14, 2015. Chiapas - México. Anais... Chiapas. XIV CIAEM.

LIMA, I.; MARTINS, R. L. Concepções sobre a matemática mobilizadas por professores de licenciaturas. In: SEMINÁRIO INTERNACIONAL DE PESQUISA EM EDUCAÇÃO MATEMÁTICA, 5, 2012. Petrópolis - RJ. Anais... V SIPEM, 2012. 
PAVANELlO, R. M. (1993). O abandono do ensino de geometria no Brasil: causas e consequências - Zetetiké, 1 (1), 7-17

PIROLA, N. A. Solução de problemas geométricos: dificuldades e perspectivas. 2000.

245p. Tese (Doutorado em Educação Matemática) - Universidade Estadual de Campinas, Unicamp, Campinas.

SCHROEDER, T. L.; LESTER, F. K., JR. Developing understanding in mathematics via problem solving. In: TRAFTON, P. R.; SHULTE, A. P. (Ed.). New directions for elementary school mathematics. Reston: NCTM, 1989, p. 31-42.

SHULMAN, L. S. Those who understand: the knowledge growth. In: Teaching Educational Researcher, 1986, 4-14.

SOUSA, V. G. SOBRINHO, J. A. C. M. A formação matemática no curso de pedagogia da UFPI: revelando olhares. In: ENCONTRO DE PESQUISA EM EDUCAÇÃO da UFPI, 6. 2010. Anais... Piaui, 2010.

TOZONI-REIS, M. F. C. A pesquisa e a produção de conhecimentos. In: PINHO, S. Z. (Org.). Cadernos de Formação: Formação de Professores. Educação, Cultura e Desenvolvimento. Volume 3. São Paulo: Cultura Acadêmica, 2010, p. 111-148. 